\title{
Occupational health of Iranian farmworkers: A public health priority
}

\author{
Mahin Ghafari ${ }^{1}$, Zahra Cheraghi ${ }^{2}$, Amin Doosti-Irani ${ }^{2 *}$ \\ Received: 23 Feb $2017 \quad$ Published: 18 Dec 2017
}

Copyright@ Iran University of Medical Sciences

Cite this article as: Ghafari M, Cheraghi Z, Doosti-Irani A. Occupational health of Iranian farmworkers: A public health priority. Med J Islam Repub Iran. 2017 (18 Dec);31:105. https://doi.org/10.14196/mjiri.31.105

\section{Dear Editor-in-Chief}

In developing countries, progress towards agricultural goals is paramount; and thus farmworkers are one of the most important human resources in each community. In Iran, farming is a highly important foundation in the lives of people, and farmers have an essential role in the country's socioeconomic growth (1). In 2015, more than $18 \%$ of employees (approximately 4 million people) in Iran were working in the agricultural sector (2).

Agriculture is known as a high-risk job (3). Therefore, the health of farmworkers is a major concern for health policymakers worldwide (4). Chemical, ergonomic, biological, and physical hazards threaten the health of farmworkers (5-7). The chemical risk factors, which include exposure to pesticides in the agricultural setting, increase the risk of cancers among farmworkers (8). Moreover, exposure to biological risk factors increases the risk of occupational infectious diseases such as leptospirosis, Q fever, brucellosis, avian influenza, and fungal infectious diseases $(9,10)$. Furthermore, accidents, injuries, and falls are other hazards that threaten the lives of farmworkers $(11,12)$. Iranian farmworkers, like farmworkers in other countries, encounter occupational risk factors and workrelated injuries. However, in Iran, there is no comprehensive health surveillance system for agriculture-related diseases and injuries. According to health indicators in Iran in 2010 , only $32 \%$ of the farmworkers were identified by Iran's health system, and of them, $18.7 \%$ were covered by occupational health care services and regular screening tests (13). These indicators revealed that substantial proportions $(81.3 \%)$ of Iranian farmworkers are not covered by occupational health care services. To date, only few epidemiological studies have been conducted on the occupational health of farmworkers in Iran. However, given that a board range of risk factors threaten the health of this group, the available evidence on the occupational risk factors of farmworkers is not sufficient for Iranian health policymakers. Therefore, we have the following recommendations to improve the health status of Iranian farmworkers: (1) a registry system should be developed for occupation-related disease and injuries of farmworkers; (2) the departments of occupational health at the national and subnational levels should pay more attention to the health of Iranian farmworkers; and (3) researchers in the field of occupational health and epidemiology must determine research priorities for the assessment of health problems of Iranian farmworkers.

\section{Conflict of Interests}

The authors declare that they have no competing interests.

\section{References}

1. McLachlan KS. The neglected garden: The politics and ecology of agriculture in Iran: IB Tauris; 1988.

2. Statistical center of Iran. Census of agriculture [02 February 2017]. Available from: https://www.amar.org.ir/.

3. Stoleski S, Minov J, Mijakoski D. Bronchial Hyperresponsiveness in Farmers: Severity and Work-Relatedness. Maced J Med Sci. 2014;7(3):536-43.

4. Donham KJ. Agricultural occupational and environmental health: policy strategies for the future. Appl Indust Hyg. 1989;4(10):F-12-F22.

5. Geng Q, Stuthridge RW, Field WE. Hazards for Farmers With Disabilities: Working in Cold Environments. J Agromedicine. 2013;18(2): 140-50

6. Cha ES, Jeong M, Lee WJ. Agricultural Pesticide Usage and Prioritization in South Korea. J Agromedicine. 2014;19(3):281-93.

7. Guthrie R, Westaway J, Goldacre L. Workers compensation and occupational health and safety in the Australian agricultural industry. Aust J Rural Health. 2009;17(2):77-85.

8. De Roos AJ, Blair A, Rusiecki JA, Hoppin JA, Svec M, Dosemeci M, et al. Cancer incidence among glyphosate-exposed pesticide applicators in the Agricultural Health Study. Environ Health Perspect.

Corresponding author:Dr Amin Doosti-Irani, a_doostiirani@yahoo.com

\footnotetext{
1. Department of Public Health, School of Health, Shahrekord University of Medical Sciences, Shahrekord, Iran.

2. Department of Epidemiology, School of Public Health, Hamadan University of Medical Sciences, Hamadan, Iran.
} 
2005;113(1):49-54

9. Monno R, Fumarola L, Trerotoli P, Cavone D, Giannelli G, Rizzo C, et al. Seroprevalence of $\mathrm{Q}$ fever, brucellosis and leptospirosis in farmers and agricultural workers in Bari, Southern Italy. Ann Agric Environ Med. 2009;16(2):205-9.

10. Obradovic-Tomasev M, Jovanovic M, Vuckovic N, Popovic A. Fungal infections in corn picker hand injury. Srpski arhiv za celokupno lekarstvo. 2016;144(1-2):52-5.

11. Tonozzi TR, Layne LA. Hired crop worker injuries on farms in the United States: A comparison of two survey periods from the National Agricultural Workers Survey. Am J Ind Med. 2016;59(5):408-23.

12. Fox S, Ricketts M, Minton JE. Worker injuries involving the interaction of cattle, cattle handlers, and farm structures or equipment. J Agric Saf Health. 2015;21(1):3-12.

13. Deputy for health Ministry of health and medical education. Health indicators in Iran, 2006-2010. Tehran. Available from: http:// markazsalamat.behdasht.gov.ir/. 